\title{
Expiratory Vital Capacity
}

National Cancer Institute

\section{Source}

National Cancer Institute. Expiratory Vital Capacity. NCI Thesaurus. Code C147484.

The maximum volume of air an individual can exhale from the point of maximal inhalation. 